\title{
Impacto y análisis de las normas internacionales en el desarrollo de las funciones del revisor fiscal en Colombia ${ }^{1}$
}

\author{
Mónica Alexandra Ahumada Quiroga² \\ Edwin Steven Matallana Chilito ${ }^{3}$ \\ David Leonardo Ardila Segura ${ }^{4}$
}

Recibido: 15 de julio de 2016

Aprobado: 19 de octubre de 2016

\begin{abstract}
Ahumada, M., Matallana, E., y Ardila, D. (2016). Impacto y análisis de las normas internacionales en el desarrollo de las funciones del revisor fiscal en Colombia. Activos, 27, 101-142.
\end{abstract}

Clasificación JEL: M42.

\section{Resumen}

Históricamente, el papel del contador público ha sido necesario y fundamental para el desarrollo económico de una empresa, en Colombia a los profesionales de la Contaduría Pública se le otorgó la capacidad de ejercer

1 Documento de investigación formativa, presentado al XI Congreso de Estudiantes de Contaduría Pública - USTA, realizado los días 6 y 7 de mayo en la ciudad de Bogotá, Colombia; acreedor del tercer puesto en el concurso de ponencias de dicho evento.

2 Estudiante de la Facultad de Contaduría Pública, Universidad Santo Tomás. Correo electrónico: monicaahumada@usantotomas.edu.co

3 Estudiante de la Facultad de Contaduría Pública, Universidad Santo Tomás. Correo electrónico: edwinmatallana@usantotomas.edu.co

4 Estudiante de la Facultad de Contaduría Pública, Universidad Santo Tomás. Correo electrónico: davidardila@usantotomas.edu.co 
como revisor fiscal, figura que sirve como un soporte para el Estado y así brindar seguridad a los inversionistas y demás usuarios de la información contable y financiera.

En los últimos años la profesión del contador público ha tenido cambios importantes en su normatividad y en su enfoque, gracias a los cambios impulsados por la armonización del lenguaje contable con respecto a la adopción de las Normas Internacionales de Información Financiera - NIIF, las cuales van a permitir que el contador público sea más analítico y tenga más participación en la toma de decisiones en las empresas.

El documento realiza un análisis de la función de la revisoría fiscal en el marco de la convergencia a NIIF, y los potenciales y limitaciones del desarrollo de su actividad en este contexto.

\title{
Palabras clave
}

Revisoría fiscal, normas internacionales de auditoria, Normas Internacionales de Información Financiera, estados financieros, profesional contable.

\section{Ahumada, M., Matallana, E., y Ardila, D. (2016). Impact and analy- sis of international financial reporting standards in development of "revisor fiscal" functions in Colombia. Activos, 27, 101-142.}

\begin{abstract}
Historically, the public accountant role is necessary and fundamental for economic development of organizations, in Colombia to profesionals of public accounting were granted the capacity of exercise like "revisor fiscal", figure that served like an State support for giving security for investors and other accounting and financial information users.

5 Hay que señalar que el concepto "revisor fiscal" en su sentido de auditor general interno de las organizaciones no tiene parangón en el mundo anglosajón, y por ende no hay un vocablo adecuado para designarlo (N. del E.).
\end{abstract}


In the last years the public accountant profession has been important changes in these regulation and focus, thanks to the changes driven for the harmonization of accountant language in the frame of International Financial Reporting Standards (IFRS), which will alow that the public accounting be more analytic and more participative in take decisions of organization.

This paper makes an analysis of "revisor fiscal" functions in the frame of convergence to IFRS, and potentials and limitations of their activiti development in these context.

\title{
Keywords
}

Revisoría fiscal, International Financial Reporting Standards, international auditing standards, financial statements, accounting professional.

\author{
Ahumada, M., Matallana, E., y Ardila, D. (2016). Impact et analyse \\ des normes internationales dans le développement des fonctions \\ du contrôleur fiscal en Colombie. Activos, 27, 101-142.
}

\section{Résumé}

Historiquement, le rôle de l'expert-comptable a été nécessaire et indispensable au développement économique d'une entreprise, en Colombie les professionnels du domaine comptable ont le droit d'exercer comme contrôleur fiscal, rôle qui sert de soutien à l'État et qui permet ainsi d'assurer une sécurité aux investisseurs et aux autres utilisateurs de l'information comptable et financière.

Ces dernières années, la profession d'expert-comptable a subi d'importants changements dans ses dispositions et dans son approche, grâce aux changements induits par l'harmonisation du langage comptable en ce qui concerne l'adoption des Normes Internationales d'Information Financière - NIIF, lesquelles vont permettre à l'expert-comptable d'être plus analytique et d'avoir une plus grande participation dans la prise de décisions des entreprises. 
Le document analyse le rôle du contrôle fiscal dans le cadre de la convergence à NIIF, et le potentiel et les limites du développement de son activité dans ce contexte.

\section{Mots-clés:}

Audit fiscal, normes internationales d'audit, Normes Internationales d'Information Financière, états financiers, expert-comptable.

\section{Introducción}

En Colombia la función del revisor fiscal es muy importante, en la medida en que es una figura de control para el Estado y aseguramiento para los intereses de los usuarios de la información financiera de una organización, la cual se garantiza en el ejercicio de dar fe pública. La figura de la Fe Pública nació a mediados del siglo XX por medio de la Ley 73 de 1935 y fue asignada al contador público como función privativa por medio del Decreto 2373 de 1956.

Actualmente, de acuerdo a los cambios que han surgido en la normatividad contable colombiana principalmente por la adopción de las Normas Internacionales de Información Financiera, la figura de revisoría fiscal ha tenido una dinámica a los cambios que impone esta normatividad con el objetivo de asesorar de la mejor manera las necesidades contables de las organizaciones, ya que es un ente encargado de la supervisión e instrucción en el proceso de implementación de dichas normas.

A partir de la Ley 1314 de 2009 se da origen a un marco normativo orientado a la adopción de las Normas Internacionales de Información Financiera - NIIF y de Auditoría - NIAS. Esta transición de la antigua 
regulación contable dirigida por el Decreto 2649 de 1993, hacia la aplicación de la norma internacional, hace nuevamente que el papel del revisor fiscal sea modificado siempre en miras de responder con las exigencias vigentes.

El nuevo reto para el revisor fiscal, implantado por las NIIF y las NIAS será fuente de cambio y desarrollo para este, siendo que su papel debe estar en total concordancia con los estándares internacionales. Por tal motivo, es fundamental hacerse la pregunta sobre si el revisor fiscal está preparado para este nuevo reto.

Por lo anterior, es menester que se dé claridad en las modificaciones que se harán al papel que el profesional debe asumir por cuenta de la implementación de la norma internacional, ya que en el país no se ha determinado el trabajo que le corresponderá cuando se de en las empresas la contabilidad bajo NIIF plenas.

Mediante el presente documento se busca definir los aspectos que tiene en cuenta la normatividad en Colombia, actualmente establecida para la función del revisor fiscal; por otro lado indagar acerca de las funciones que proponen los estándares internacionales respecto al papel del revisor fiscal, y por último identificar las modificaciones que surgen a raíz de la aplicación de los estándares internacionales respecto a las normas actualmente establecidas.

Con esta figura tan importante en el contexto colombiano, se quiere identificar: ¿Cómo se va a ver afectada esta figura desde las normas adoptadas?, teniendo en cuenta que el revisor fiscal es un agente de control el cual cubre gran parte de los intereses del Estado y los inversionistas, sabiendo que la norma internacional no contiene dicha figura. Para darle solución a lo mencionado anteriormente, es necesario plantear la siguiente pregunta: ¿Cuál es el efecto de las NIIF y las NIAS en cuanto al papel del revisor fiscal en Colombia? 


\section{Aspectos teóricos de la revisoría fiscal en Colombia}

\section{Revisoría fiscal}

La revisoría fiscal en Colombia nació en pleno desarrollo comercial y financiero de las empresas en la segunda mitad del siglo XIX, por medio del Decreto 2373 de 1956 en el cual el Estado le otorgó al contador público la función preventiva de ejercer el control y vigilancia de un ente económico por medio de fe pública aplicada bajo las normas de auditoria generalmente aceptadas en Colombia. Dentro de sus funciones más importantes le corresponde dictaminar los estados financieros y revisar y evaluar sistemáticamente los componentes y elementos que integran el control interno.

Es de resaltar que el Consejo Técnico de la Contaduría Pública (de acuerdo a la Ley 40 de 1990, se define como: "un organismo permanente, encargado de la orientación técnica-científica de la profesión y de la investigación de los principios de contabilidad y normas de auditoría de aceptación general en el país"), en orientación profesional emitida el 21 de junio de 2008, redefinió la figura de la revisoría fiscal. Dentro de los aspectos más importantes se aclara el papel de la revisoría fiscal frente a los administradores o gerentes de la empresa.

De igual forma, se le da al revisor fiscal la facultad de un fiscal empresarial el cual tiene la posibilidad de examinar las operaciones del ente económico y así dar una opinión sobre la información financiera de acuerdo a su procedimiento de auditoria. Gracias a dichos procedimientos realizados tiene el poder de evaluar e informar conductas y comportamientos oportunamente, con el objetivo de brindar seguridad de la información financiera a todos los usuarios y entes de control y de esta forma permite tomar decisiones para el crecimiento de la entidad.

Actualmente, el revisor fiscal juega un papel muy importante para el desarrollo y control de las operaciones de las empresas en Colombia. Sin embargo, debido a los cambios que se han presentado en la normatividad contable, el papel del revisor fiscal se debe fortalecer, así como la 
normatividad y los requisitos que se tienen establecidos para que el profesional pueda ejercer esta función. Resaltando que en la actualidad todo contador público titulado con tarjeta profesional puede ser revisor fiscal.

Cabe destacar que, en el ejercicio de revisor fiscal, se han otorgado funciones como la de firmar y certificar en muchas ocasiones temas que aunque estén dentro de su alcance al tener cifras contables en las mismas, no están acordes a la función primordial que es la opinión a los estados financieros. Por lo tanto, sería indispensable que los entes de control evaluaran aquellos aspectos y se analizara si es necesario con el cambio a normas internacionales que este profesional, primero para ser revisor fiscal, cuente con estudios, con más experiencia y de igual forma sean concretos en las funciones de este profesional y no se le otorguen responsabilidad en temas que como se comentó anteriormente, afectan las funciones establecidas en la normatividad y de las cuales más adelante se abordará con mayor profundidad.

\section{Fe pública}

Teniendo en cuenta que la información contable tiene como principal función la toma de decisiones por parte de la empresa, como también que los usuarios de la información puedan acceder a la misma para que de esta forma también puedan tomar decisiones ya sea para invertir, proveer o controlar, por lo tanto es necesario que esta sea presentada de forma razonable, y es donde las funciones del revisor fiscal toman un rumbo indicado, el cual es la seguridad y confiabilidad de la información.

La Ley 45 de 1990 en el artículo 10 expresa de la siguiente forma la función con la cual se debe regir al momento de emitir el dictamen del revisor fiscal y por tanto los procedimientos desarrollados durante la aplicación de su trabajo correspondiente:

De la fe pública. La atestación o firma de un contador público en los actos propios de su profesión hará presumir, salvo prueba en contrario, que el acto respectivo se ajusta a los requisitos legales, lo mismo que a los 
estatutarios en casos de personas jurídicas. Tratándose de balances, se presumirá además que los saldos se han tomado fielmente de los libros, que estos se ajustan a las normas legales y que las cifras registradas en ellos reflejan en forma fidedigna la correspondiente situación financiera en la fecha del balance (Ley 45 de 1990, artículo 10).

De acuerdo a Moya (2007), la firma como contador público y por tanto quien a su vez actúe como revisor fiscal afirma que la información es razonable y verídica, esta responsabilidad hace de la profesión un hecho riesgoso en caso de actuar de forma errónea. Por tal razón en dicha ley impuesta por el Congreso de la República, se busca que al ser firmados los estados financieros o cualquier tipo de información financiera, exista la confianza que dicho acto representa y que las funciones se desarrollan de la forma adecuada.

\section{Ejercicio y funciones}

Las principales funciones del revisor fiscal se encuentran reglamentadas en el artículo 207 del Código de Comercio y en el artículo 27 de la Ley 1762 de 2015, las cuales se ilustran en la figura 1 . 
Figura 1. Principales funciones del revisor fiscal.

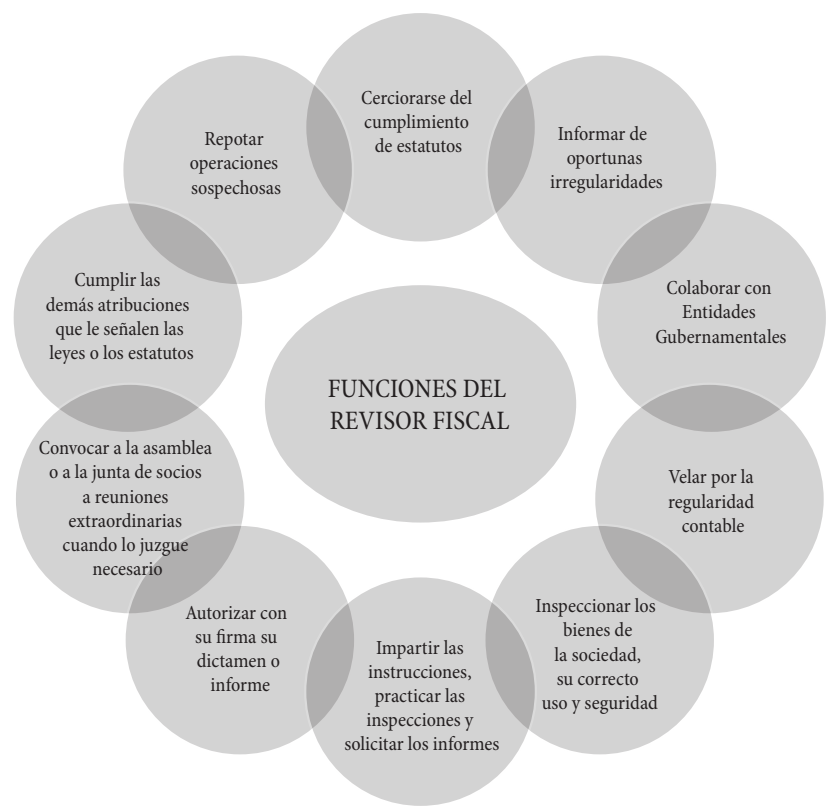

Fuente: elaboración propia a partir del Código de Comercio, artículo 207.

\section{Obligados a tener revisor fiscal}

El Código de Comercio específica en el artículo 203 las sociedades que están obligadas a tener revisor fiscal, tal como se indica en la tabla 1.

Tabla 1. Entidades obligadas a tener revisor fiscal.

\begin{tabular}{l|l|l}
\hline & \multicolumn{2}{|c}{ Sociedades obligadas a tener revisor fiscal } \\
\hline Sociedades por & $\begin{array}{l}\text { Sucursales de las } \\
\text { acciones }\end{array}$ & $\begin{array}{l}\text { Las sociedades en las que, por ley o } \\
\text { por lostatutos, la administración no } \\
\text { corresponda a todos los socios, cuando } \\
\text { así lo disponga cualquier número de } \\
\text { socios excluidos de la administración que } \\
\text { representen no menos del 20 \% del capital. }\end{array}$ \\
\hline
\end{tabular}

Fuente: elaboración propia, a partir del Código de Comercio, artículo 203. 
110 ACTIVos | Mónica Alexandra Ahumada Quiroga, Edwin Steven Matallana Chilito, David Leonardo Ardila Segura

De acuerdo a lo anterior, la ley 43 de 1990 en el artículo 13, parágrafo 2 dictamina lo siguiente:

Será obligatorio tener revisor fiscal en todas las sociedades comerciales, de cualquier naturaleza, cuyos activos brutos al 31 de diciembre del año inmediatamente anterior sean o excedan el equivalente de cinco mil salarios mínimos y/o cuyos ingresos brutos durante el año inmediatamente anterior sean o excedan al equivalente a tres mil salarios mínimos.

Las empresas deben cumplir con los parámetros expuestos tanto por el Código de Comercio como por las leyes dictaminadas por el Congreso de la República.

\section{Elección del revisor fiscal y enfoques de la revisoría fiscal}

Tabla 2. Elección y enfoque del revisor fiscal.

\begin{tabular}{|c|c|}
\hline Elección del revisor fiscal & Enfoque de la revisoría fiscal \\
\hline $\begin{array}{l}\text { 1. La elección del revisor fiscal se } \\
\text { hará por la mayoría absoluta de la } \\
\text { asamblea o de la junta de socios. }\end{array}$ & $\begin{array}{l}\text { 1. Órgano societario (de control): el } \\
\text { Código de Ética de IESBA señala que la } \\
\text { independencia del contador profesional en } \\
\text { ejercicio público tiene que ser tanto en la } \\
\text { mente como en la apariencia. }\end{array}$ \\
\hline $\begin{array}{l}\text { 2. En las comanditarias por accio- } \\
\text { nes, el revisor fiscal será elegido } \\
\text { por la mayoría de votos de los } \\
\text { comanditarios. }\end{array}$ & $\begin{array}{l}\text { 2. Órgano de fiscalización: es una figura } \\
\text { en la cual se ha insistido bastante para } \\
\text { contraponerla a la auditoría. }\end{array}$ \\
\hline $\begin{array}{l}\text { 3. En las sucursales de sociedades } \\
\text { extranjeras lo designará el órgano } \\
\text { competente de acuerdo con los } \\
\text { estatutos. }\end{array}$ & $\begin{array}{l}\text { 3. Sumatoria de auditorías: es una pro- } \\
\text { puesta acogida e incorporada por algunas } \\
\text { superintendencias }\end{array}$ \\
\hline $\begin{array}{l}\text { 4. Las actas son el método idóneo } \\
\text { probatorio sobre las decisiones } \\
\text { de la Asamblea, conforme a las } \\
\text { normas legales. }\end{array}$ & $\begin{array}{l}\text { 4. Rol de aseguramiento independiente } \\
\text { (auditoría de los estados financieros): } \\
\text { está derivada de las prácticas de gobierno } \\
\text { corporativo y a ella responden los estánda- } \\
\text { res internacionales de auditoría (ISA/NIA) } \\
\text { y de información financiera (IFRS/NIIF). }\end{array}$ \\
\hline
\end{tabular}

Fuente: elaboración propia de acuerdo a Moya (2007), la elección del revisor fiscal se expone en el artículo 204 del Código de Comercio. 
En la tabla 2 se resaltan las principales características de la elección del revisor fiscal, la cual debe quedar estipulada en las actas de asamblea de accionistas, así como el enfoque que el revisor fiscal manejará a lo largo de su auditoría.

\section{Aspecto normativo de la revisoría fiscal}

Tabla 3. Aspecto normativo de la revisoría fiscal.

\begin{tabular}{|c|c|c|}
\hline $\begin{array}{l}\text { Ley } 43 \text { del } 13 \text { de di- } \\
\text { ciembre de } 1990\end{array}$ & $\begin{array}{l}\text { Decreto } 302 \text { del } 20 \text { de } \\
\text { febrero de } 2015\end{array}$ & $\begin{array}{l}\text { Circular externa } \\
115-000011 \text { del } 21 \text { de } \\
\text { octubre de } 2008\end{array}$ \\
\hline $\begin{array}{l}\text { De acuerdo al art. } 7 \text { de esta } \\
\text { ley, las normas de auditoria } \\
\text { son las siguientes: } \\
\text { Normas personales: se } \\
\text { refieren al perfil que debe } \\
\text { tener la persona que realice } \\
\text { algún informe o prueba de } \\
\text { auditoría. } \\
\text { Normas relativas a la } \\
\text { ejecución del trabajo: se } \\
\text { refieren a los aspectos im- } \\
\text { portantes los cuales debe } \\
\text { tener presente el auditor o } \\
\text { el revisor fiscal al momento } \\
\text { de realizar sus papeles de } \\
\text { trabajo. } \\
\text { Normas relativas a la } \\
\text { redición de informes: } \\
\text { se especifican los puntos } \\
\text { básicos que se deben tener } \\
\text { en cuenta al momento } \\
\text { de elaborar y presentar } \\
\text { informes con respecto a } \\
\text { las auditorias y revisiones } \\
\text { realizadas. }\end{array}$ & $\begin{array}{l}\text { El decreto establece algunos } \\
\text { artículos en los cuales se } \\
\text { aborda el perfil y la impor- } \\
\text { tancia del revisor fiscal: } \\
\text { Artículo 2: el decreto será } \\
\text { de aplicación obligatoria } \\
\text { por los revisores fiscales } \\
\text { que presten sus servicios a } \\
\text { entidades del grupo } 1 \text { y a } \\
\text { las entidades del grupo } 2 \\
\text { que tengan más de } 30.000 \\
\text { salarios mínimos legales } \\
\text { vigentes de activos, o más } \\
\text { de } 200 \text { trabajadores. } \\
\text { Artículo 3: se explica } \\
\text { que el revisor fiscal deberá } \\
\text { aplicar las NIAS, en rela- } \\
\text { ción con el dictamen a los } \\
\text { estados financieros. } \\
\text { Artículo 4: menciona que } \\
\text { el revisor fiscal aplicará } \\
\text { las ISAE, relacionadas con } \\
\text { la evaluación del cumpli- } \\
\text { miento de las disposiciones } \\
\text { estatutarias y de la asam- } \\
\text { blea o junta de socios. }\end{array}$ & $\begin{array}{l}\text { En esta circular expedida } \\
\text { por la Superintendencia } \\
\text { de Sociedades abarca el } \\
\text { tema de la revisoría fiscal } \\
\text { desde un enfoque especifico, } \\
\text { teniendo en cuenta su marco } \\
\text { conceptual y normativo, las } \\
\text { funciones de la revisoría } \\
\text { fiscal, sus criterios objetivos } \\
\text { y calidades subjetivas y las } \\
\text { normas relativas a la rendi- } \\
\text { ción de informes, al final de } \\
\text { esta circular se trata el tema } \\
\text { del alcance de las funciones } \\
\text { del revisor fiscal es impor- } \\
\text { tante resaltar lo siguiente. } \\
\text { El revisor fiscal en cumpli- } \\
\text { miento de sus funciones } \\
\text { debe realizar labores de } \\
\text { auditoría financiera, de cum- } \\
\text { plimiento y de auditoria al } \\
\text { sistema de control interno. }\end{array}$ \\
\hline
\end{tabular}

Fuente: elaboración propia a partir de la Ley 43 de 1990, artículo 7, Decreto 302 del 20 de febrero de 2015 y la Circular Externa 115-000011 del 21 de octubre de 2008. 
A continuación se mencionarán algunas leyes, decretos y artículos en los cuales se hablar sobre la importancia de la revisoría fiscal y las normas que se deben tener en cuenta para el desarrollo de sus funciones en la actualidad.

El marco normativo de la revisoría fiscal se encuentra definido, entre otras disposiciones, por el Código de Comercio, la Ley 145 de 1960, la Ley 43 de 1990, la Ley 45 de 1990, la Ley 190 de 1995, la Ley 222 de 1995 y el Decreto 2649 de 1993 (ver tabla 3).

\section{Principios éticos en la práctica de la revisoría fiscal}

Uno de los principios más importantes por los cuales se debe regir la profesión contable es la confianza en la información, durante los últimos años la profesión se ha visto enmarcada en diferentes casos de corrupción, ya sea por dictaminar estados financieros "maquillados" los cuales no presentan la información contable de forma veraz, por tal razón la imagen del contador público ha perdido credibilidad y de aquí la importancia de recuperar la confianza de los usuarios de la información, para recuperar dicha credibilidad, y teniendo en cuenta lo dicho por Peña (2011) a través de nueve principios se puede obtener y ganar la confianza pública:
1. Independencia
6. Permanencia
2. Idoneidad
7. Integralidad
3. Objetividad
8. Dictamen y atestación
4. Confidencialidad
9. Evidencia
5. Oportunidad
10. Diligencia profesional

Los anteriores principios buscan que el revisor fiscal actúe de la forma correcta, generando credibilidad en su actuar, el conocimiento de dichos principios entre la comunidad profesional es fundamental para mejorar el entorno de acción de los revisores, y en general de los involucrados en las labores de control organizacional. 


\section{La revisoría fiscal y las normas internacionales}

\section{Diferencias entre revisor fiscal y auditoría}

Para establecer las funciones del revisor fiscal bajo las normas internacionales es necesario identificar las funciones del auditor, en la tabla 4 se evidencia un paralelo entre las dos figuras aplicadas bajo el marco nacional e internacional.

Tabla 4. Diferencias entre las funciones del revisor fiscal y del auditor.

\begin{tabular}{l|l}
\hline Revisor fiscal & \multicolumn{1}{l}{ Auditor } \\
\hline $\begin{array}{l}\text { Tiene la responsabilidad de fiscalizar y } \\
\text { controlar los hechos económicos. }\end{array}$ & $\begin{array}{l}\text { Tiene total independencia en aplicar su } \\
\text { criterio y emplear sus instrumentos de } \\
\text { auditoria. }\end{array}$ \\
\hline $\begin{array}{l}\text { La revisoría fiscal es de función continua, } \\
\text { lo que quiere decir que su servicio lo pres- } \\
\text { ta a la entidad por un término semejante } \\
\text { al de la Junta Directiva. }\end{array}$ & $\begin{array}{l}\text { La auditoría se presta por labor realizada, } \\
\text { una vez generado la opinión de los estados } \\
\text { financieros, se tiene por entendido finali- } \\
\text { zado el contrato. }\end{array}$ \\
\hline $\begin{array}{l}\text { Más allá de emitir una opinión acerca de } \\
\text { la razonabilidad de los estados financieros, } \\
\text { el revisor fiscal tiene la responsabilidad de } \\
\text { evaluar el cumplimiento de normas que } \\
\text { regula la información contable a emitir. }\end{array}$ & $\begin{array}{l}\text { El auditor solo se enfoca en la inspección } \\
\text { de la existencia de los saldos y el ejercicio } \\
\text { de buenos procesos. }\end{array}$ \\
\hline $\begin{array}{l}\text { Está obligado a generar diversos tipos de } \\
\text { certificaciones durante el periodo de su } \\
\text { ejercicio, informes de las evaluaciones que } \\
\text { efectúa de acuerdo con su plan de trabajo, } \\
\text { dictamen sobre los estados financieros } \\
\text { y debe producir un informe adicional } \\
\begin{array}{l}\text { a la Asamblea de accionistas acerca del } \\
\text { cumplimiento de requisitos adicionales a } \\
\text { la auditoría financiera. }\end{array}\end{array}$ & $\begin{array}{l}\text { Genera un memorando de recomendacio- } \\
\text { nes como resultado de su evaluación y un } \\
\text { la razonabilidad de los estados financie- } \\
\text { ros, en los términos exigidos dentro del } \\
\text { concepto de seguridad razonable. }\end{array}$ \\
\hline
\end{tabular}

Fuente: elaboración propia a partir de Bernal, Penagos y Penagos (2014). 
Para entender de forma más precisa las funciones que recaen sobre la figura del revisor fiscal en comparación con el auditor, es importante aclarar en primera instancia que el revisor fiscal es una figura netamente colombiana, mediante la cual más que emitir una opinión se usa para certificar todo tipo de acciones de una empresa.

Por tal motivo y teniendo en cuenta el paralelo anteriormente realizado, una de las principales funciones del revisor fiscal es la responsabilidad de fiscalizar y controlar los hechos económicos, cabe mencionar que al momento de consagrar su firma ya sea mediante una certificación, declaración de información o dictamen, el revisor asume la responsabilidad de que aquello que ha firmado ha sido revisado y por tanto ha sido tomado fielmente de los estados financieros de una empresa, lo cual será útil para la toma de decisiones.

El servicio prestado por parte de la revisoría fiscal podrá ejercerlo por un tiempo semejante al ejercido por parte de la Junta Directiva, de acuerdo a lo estipulado en el Código de Comercio, artículo 206.

Uno de los puntos relevantes a tener en cuenta es que el revisor fiscal no está encargado únicamente de dictaminar los estados financieros, además de esto debe dar cumplimiento a toda la normativa, la cual es impartida por los órganos de control encargados los cuales pueden ser dictaminados mediante una ley por parte del Congreso o a través de las Superintendencias, las cuales regulan y llevan control sobre las empresas colombianas de acuerdo al sector en que se desarrollen.

Así mismo, durante su ejercicio está encargado de certificar y declarar todo tipo de información a la cual esté obligado para dar cumplimiento a la normativa y por tanto a los órganos de control que soliciten la firma del revisor, cabe destacar que todas las certificaciones deberán contener información financiera la cual será útil para la toma de decisiones.

Por otro lado, se encuentra la figura del auditor la cual está directamente relacionada a las Normas Internacionales de Aseguramiento (NIA), debido 
a que esta figura difiere del revisor fiscal en varios de los aspectos tales como la total independencia con la que cuenta el auditor para emplear su criterio, y por tanto dar una opinión razonable de los saldos de los estados financieros, empleando sus instrumentos de auditoría para realizar una evaluación adecuada para cada una de las cuentas; derivada la opinión emitida por el mismo se da por terminado el contrato, es decir el auditor es contratado exclusivamente para realizar una evaluación específica de la situación financiera de una empresa a partir de la cual se puedan corregir los procedimientos y se puedan observar oportunidades de mejora, por tanto la única responsabilidad es cumplir con su trabajo emitiendo su opinión al respecto.

El alcance del trabajo del auditor se remite a la emisión de un memorando de recomendaciones en el cual plasma de forma clara todas las observaciones encontradas a partir de su evaluación, de este memorando se desprende que los saldos expresados en los estados financieros son fiel copia de los libros contables y cuentan con la seguridad razonable, adecuada para una efectiva toma de decisiones.

De acuerdo a la información que se estableció en la tabla anterior, se fundamentan los siguientes enfoques de control:

Tabla 5. Enfoque de control.

\begin{tabular}{l|c|c}
\hline Sector & Público & Privado \\
\hline Principal & Ciudadano & Accionistas/socios \\
\hline Tercero & Revisor fiscal & Auditor externo \\
\hline Agente & Gobierno & Administrador \\
\hline
\end{tabular}

Fuente: elaboración propia.

Con la Ley 43 de 1990, se rige la figura del revisor fiscal hacia un enfoque de auditoría financiera en donde el Estado no está involucrado, generando una contradicción con la perspectiva de las normas anteriores, las cuales basaban su criterio en el control latino, en cual el Estado participa activamente en las empresas. 


\section{¿Cómo debería actuar la revisoría fiscal y cómo se ha asentado hoy por hoy con la adopción de la Ley 1314 de 2009?}

De acuerdo a la globalización que se ha venido presentado en los últimos años, los países han adoptado las Normas Internacionales de Información Financiera - NIIF, para mejorar la estabilidad de la economía e incrementar el acceso de las empresas a los mercados de capitales. En Colombia, mediante la Ley 1314 se estable una estructura normativa, para que las empresas empiecen una adopción de las NIIF. Con lo anterior, tanto el gobierno como las empresas y los profesionales, deberán prepararse para esta implementación con el fin de generar una estandarización de la presentación de las normas a nivel internacional.

Una de las modificaciones que surgirán a partir de la implementación de la Ley 1314 de 2009, es que anteriormente la responsabilidad y manejo de información recaía en la firma de auditoría, ahora la responsabilidad es de una sola persona, la cual será denominada como revisor fiscal, rigiéndose bajo los requerimientos del Código de Ética para Contadores Profesionales de IFAC y con la Norma Internacional de Control de Calidad.

A partir de la aplicación de la normatividad internacional, la contabilidad del país debió ajustarse, tanto así, que para una de las figuras que trabajaba en torno a la contabilidad fiscal (revisor fiscal) surgió una serie de modificaciones en sus funciones las cuales se presentan a continuación: 
Tabla 6. Comparación funciones del revisor fiscal de acuerdo a la norma colombiana y a la norma internacional.

\begin{tabular}{|c|c|c|}
\hline \multicolumn{3}{|c|}{ Revisor fiscal } \\
\hline Norma colombiana & $\begin{array}{l}\text { Normas internaciona- } \\
\text { les (NIA-NIIF) }\end{array}$ & Modificaciones \\
\hline $\begin{array}{l}\text { 1. Certificar que las ope- } \\
\text { raciones realizadas en } \\
\text { las empresas cumplan } \\
\text { con las leyes del Estado } \\
\text { y las políticas de la } \\
\text { entidad. }\end{array}$ & $\begin{array}{l}\text { 1. El revisor fiscal deberá } \\
\text { evaluar que las opera- } \\
\text { ciones se ejecuten de } \\
\text { acuerdo a las disposi- } \\
\text { ciones legales. }\end{array}$ & 1. Permanece igual. \\
\hline $\begin{array}{l}\text { 2. Informar a las directi- } \\
\text { vas de la organización } \\
\text { acerca de posibles } \\
\text { irregularidades que } \\
\text { puedan alterar el nor- } \\
\text { mal funcionamiento de } \\
\text { las actividades. }\end{array}$ & $\begin{array}{l}\text { 2. Comunicación con } \\
\text { quienes gobiernan la } \\
\text { entidad. }\end{array}$ & 2. Permanece igual. \\
\hline $\begin{array}{l}\text { 3. Acompañar a las enti- } \\
\text { dades gubernamentales } \\
\text { a ejercer la inspección, } \\
\text { vigilancia o control de } \\
\text { las empresas e informar } \\
\text { cuando haya lugar o le } \\
\text { sean solicitados. }\end{array}$ & $\begin{array}{l}\text { 3. Cumplir de forma } \\
\text { adecuada los requeri- } \\
\text { mientos solicitados por } \\
\text { las entidades guberna- } \\
\text { mentales encargadas } \\
\text { de la inspección y } \\
\text { vigilancia de las empre- } \\
\text { sas, entendiendo que se } \\
\text { debe informar cuando } \\
\text { haya lugar respecto a } \\
\text { los estados financieros. }\end{array}$ & $\begin{array}{l}\text { 3. Asegurar que el revisor } \\
\text { fiscal atienda los } \\
\text { requerimientos de las } \\
\text { entidades guberna- } \\
\text { mentales a partir de los } \\
\text { estados financieros. }\end{array}$ \\
\hline $\begin{array}{l}\text { 4. Velar porque la } \\
\text { información contable } \\
\text { se realice bajo los } \\
\text { principios de conta- } \\
\text { bilidad generalmente } \\
\text { aceptados (PCGA), y } \\
\text { así mismo se realicen } \\
\text { las actas pertinentes a } \\
\text { raíz de las reuniones } \\
\text { de asambleas, junta de } \\
\text { socios y junta directiva. }\end{array}$ & $\begin{array}{l}\text { 4. Verificar el proceso } \\
\text { contable de la empresa } \\
\text { y conservar la docu- } \\
\text { mentación pertinente } \\
\text { al periodo evaluado. }\end{array}$ & $\begin{array}{l}\text { 4. Enfoque directamente a } \\
\text { los estados financieros }\end{array}$ \\
\hline
\end{tabular}




\begin{tabular}{|c|c|c|}
\hline \multicolumn{3}{|c|}{ Revisor fiscal } \\
\hline Norma colombiana & $\begin{array}{l}\text { Normas internaciona- } \\
\text { les (NIA-NIIF) }\end{array}$ & Modificaciones \\
\hline $\begin{array}{l}\text { 5. Inspeccionar constan- } \\
\text { temente los activos de } \\
\text { la empresa y gestionar } \\
\text { la conservación o segu- } \\
\text { ridad de los mismos. }\end{array}$ & $\begin{array}{l}\text { 5. Evaluar que el control } \\
\text { interno actúe de acuer- } \\
\text { do con las políticas y } \\
\text { procedimientos de la } \\
\text { entidad. }\end{array}$ & $\begin{array}{l}\text { 5. El revisor fiscal no se } \\
\text { hace cargo del control } \\
\text { interno, sin embargo } \\
\text { debe asegurarse que } \\
\text { exista y se ejecute de } \\
\text { forma eficiente. }\end{array}$ \\
\hline $\begin{array}{l}\text { 6. Hacer la debida planea- } \\
\text { ción para realizar las } \\
\text { inspección de manera } \\
\text { eficiente y solicitar } \\
\text { la información que } \\
\text { le permita mantener } \\
\text { un control sobre los } \\
\text { recursos de la entidad. }\end{array}$ & $\begin{array}{l}\text { 6. Solicitar la información } \\
\text { y documentación ne- } \\
\text { cesarias para realizar la } \\
\text { auditoría de los estados } \\
\text { financieros. }\end{array}$ & $\begin{array}{l}\text { 6. Enfoque directamente a } \\
\text { los estados financieros. }\end{array}$ \\
\hline $\begin{array}{l}\text { 7. Atestar con su firma } \\
\text { los estados financie- } \\
\text { ros, adicionalmente } \\
\text { desarrollar el corres- } \\
\text { pondiente dictamen o } \\
\text { informe. }\end{array}$ & $\begin{array}{l}\text { 7. Dictaminar los estados } \\
\text { financieros. }\end{array}$ & 7. Permanece igual. \\
\hline $\begin{array}{l}\text { 8. Realizar asambleas } \\
\text { extraordinarias cuando } \\
\text { lo considere necesario. }\end{array}$ & $\begin{array}{l}\text { 8. Realizar los documen- } \\
\text { tos pertinentes en el } \\
\text { momento que sea nece- } \\
\text { sario para remitirlos a } \\
\text { los órganos superiores. }\end{array}$ & $\begin{array}{l}\text { 8. El revisor fiscal no está } \\
\text { a cargo de realizar las } \\
\text { funciones adminis- } \\
\text { trativas, sin embargo } \\
\text { brinda la documenta- } \\
\text { ción pertinente. }\end{array}$ \\
\hline $\begin{array}{l}\text { 9. Cumplir las demás atri- } \\
\text { buciones que le señalen } \\
\text { las leyes o los estatutos. }\end{array}$ & $\begin{array}{l}\text { 9. El revisor fiscal deberá } \\
\text { ser independiente para } \\
\text { dar cumplimiento a la } \\
\text { Ley } 1314 \text { de } 2009 \text { y las } \\
\text { NIA. }\end{array}$ & $\begin{array}{l}\text { 9. Dar cumplimiento a } \\
\text { la Ley } 1314 \text { de } 2009 \text {, } \\
\text { respetando el principio } \\
\text { de independencia. }\end{array}$ \\
\hline
\end{tabular}

Fuente: elaboración propia. 
Teniendo en cuenta la anterior tabla aplicando la comparación entre la norma colombiana y la norma de auditoría adoptada mediante la Ley 1314 de 2009 se evidencian las principales diferencias y similitudes, en primera instancia las obligaciones legales impuestas a través de leyes y normas a las cuales sea necesario la certificación por parte del revisor fiscal en temas netamente de estados financieros estará a cargo del mismo, por lo cual no se modifica, así como no se modificará la función de informar a los directivos de la empresa cualquier tipo de irregularidad que encuentre una vez evaluados los procedimientos de auditoría y la integridad de la información.

Uno de los cambios más significativos y que promueve un mejor desempeño en las labores de esta figura es que anteriormente el revisor fiscal se encontraba obligado a certificar todo tipo de información de la empresa, lo cual hace que se distorsionen las funciones y lo obligue a firmar todo tipo de declaración. Con la adopción de los estándares internacionales su función se encamina directamente a la certificación de saldos de los estados financieros únicamente, y por tanto la necesidad de verificar que la razonabilidad de los saldos sea correcta, debido a que dicha información es útil para la toma de decisiones por parte de los usuarios. Para esto se requiere de una documentación completa de todas las actividades de la empresa y su adecuado registro contable.

Como aspectos fundamentales en los cambios de sus funciones se encuentra la verificación de una correcta evaluación y aplicación por parte del control de la empresa dando una aplicación correcta a todos los procedimientos y políticas adoptadas por la entidad de forma eficiente.

Además de esto, las funciones con la adopción de los estándares internacionales van encaminadas directamente a la revisión y dictamen de los estados financieros y su correcta aplicación de acuerdo a las NIIF, por consiguiente tanto la actualización en temas contables como de auditoría son fundamentales para llevar a cabo un proceso transparente a partir del cual se basa para identificar la veracidad y la existencia de los saldos contables. 


\section{Aspectos metodológicos}

La investigación se encuentra dentro de un enfoque cualitativo. Este, permite el desarrollo de preguntas, antes durante y después de la recolección de la información.

Por su parte, Hernández, Fernández y Baptista (2010), citado en Duque y Moreno, (2015, p. 11) señalan que dentro de las principales características de este enfoque se encuentran:

- Los investigadores plantean un problema, pero no significa que se haya conceptualizado o definido totalmente.

- Este tipo de investigación se basa en la lógica y es de carácter inductivo, van de lo particular a lo general.

- Por lo general, no se prueban hipótesis.

- Los métodos de recolección de datos no son estandarizados, no se efectúa una medición numérica, ni análisis estadísticos; más bien consiste en obtener perspectivas, experiencias y significados.

- Se utilizan instrumentos de recolección de datos con preguntas abiertas, se reúnen datos por medio de los lenguajes escritos, verbales y no verbales, como observación no estructurada, entrevistas abiertas, revisión de documentos, discusiones, experiencias, historias de vida, etc.

- Ella se fundamenta en interpretar el significado de las acciones de los seres humanos.

- Define la realidad a través de lo que interpretan los participantes de la investigación, tomando como referencia sus propias realidades.

Teniendo en cuenta la problemática establecida en la investigación, este tipo de enfoque permite el uso de instrumentos los cuales involucran 
a la población objeto de estudio y permite el alcance de información real, precisa y concreta. Lo cual es fundamental para el buen desarrollo de la investigación.

El instrumento que se escoge como diseño metodológico para el desarrollo de la investigación es la aplicación de encuestas (ver anexo 1) a un grupo de profesionales contables revisores fiscales, los cuales han tenido experiencia en normas internacionales en varios sectores y en empresas de gran trayectoria en Colombia. Una vez realizadas dichas encuestas se realizará el respectivo análisis con el fin de darle solución a los objetivos planteados.

\section{Diseño de la encuesta}

La encuesta consta de nueve preguntas de tres tipos: opción múltiple con única respuesta, opción múltiple con múltiple respuesta y por último preguntas abiertas. Están formuladas teniendo en cuenta cuatro objetivos de identificación y profundización los cuales se pueden observar en la siguiente tabla:

Tabla 7. Foco desarrollado para la encuesta a los revisores fiscales.

\begin{tabular}{|c|c|}
\hline $\begin{array}{l}\text { Objetivos de identificación } \\
\text { y profundización }\end{array}$ & $\begin{array}{l}\text { Preguntas guía para el desarrollo } \\
\text { de la investigación }\end{array}$ \\
\hline \multirow{2}{*}{$\begin{array}{l}\text { Conocimiento y desempeño en las } \\
\text { prácticas como revisor fiscal. }\end{array}$} & $\begin{array}{l}\text { ¿Desde hace cuánto tiempo ejerce las funciones de } \\
\text { revisor fiscal? }\end{array}$ \\
\hline & $\begin{array}{l}\text { ¿En qué tipo de empresa y sectores ha tenido } \\
\text { experiencia como revisor fiscal? }\end{array}$ \\
\hline $\begin{array}{l}\text { Proceso de adopción de las } \\
\text { Normas Internacionales de } \\
\text { Información Financiera - NIIF. }\end{array}$ & $\begin{array}{l}\text { De acuerdo a su criterio y experiencia profesional, } \\
\text { mencione dos aspectos positivos y dos aspec- } \\
\text { tos negativos de las Normas Internacionales de } \\
\text { Información Financiera en Colombia. } \\
\text { ¿Cree usted que con las normas internaciona- } \\
\text { les se van a aumentar o disminuir los casos de } \\
\text { corrupción o fraude financieros de las empresas } \\
\text { colombianas? }\end{array}$ \\
\hline
\end{tabular}




\begin{tabular}{|c|c|}
\hline $\begin{array}{l}\text { Objetivos de identificación } \\
\text { y profundización }\end{array}$ & $\begin{array}{c}\text { Preguntas guía para el desarrollo } \\
\text { de la investigación }\end{array}$ \\
\hline $\begin{array}{l}\text { Capacitación y preparación en los } \\
\text { temas relevantes de la adopción } \\
\text { de las Normas Internacionales de } \\
\text { Información Financiera - NIIF. }\end{array}$ & $\begin{array}{l}\text { ¿Ha tenido alguna capacitación en Normas } \\
\text { Internacionales de Información Financiera y de } \\
\text { Auditoría? } \\
\text { Cree usted que las entidades de educación superior } \\
\text { y los organismos de control han preparado a los } \\
\text { profesionales contables y han realizado seguimien- } \\
\text { to oportuno en relación a la adopción de Normas } \\
\text { Internacionales de Información Financiera en } \\
\text { Colombia. }\end{array}$ \\
\hline $\begin{array}{l}\text { Perspectiva del revisor fiscal } \\
\text { frente a la adopción de las Normas } \\
\text { Internacionales de Información } \\
\text { Financiera - NIIF. }\end{array}$ & $\begin{array}{l}\text { ¿Cómo ha sido su experiencia como revisor fiscal } \\
\text { teniendo en cuenta la adopción en Colombia } \\
\text { de las Normas Internacionales de Información } \\
\text { Financiera? } \\
\text { ¿Cree usted que se le debe dar algún cambio } \\
\text { a la función de revisoría fiscal en Colombia } \\
\text { teniendo en cuenta la adopción de las Normas } \\
\text { Internacionales de Información Financiera? } \\
\text { ¿De acuerdo a su experiencia como revisor fiscal } \\
\text { las normas internacionales tuvieron un impacto en } \\
\text { el desempeño financiero de las empresas a } 31 \text { de } \\
\text { diciembre de } 2015 ?\end{array}$ \\
\hline
\end{tabular}

Fuente: elaboración propia.

Este tipo de preguntas permitirá identificar aspectos importantes enfocados principalmente a la experiencia que han tenido estos profesionales en el ejercicio de sus funciones como revisores fiscales, teniendo en cuenta el cambio en la normatividad contable, por lo tanto este tipo de respuestas serán base esencial para identificar y analizar el impacto de las normas internacionales en el desarrollo de las funciones de revisor fiscal en Colombia. 


\section{Tipo de población a la cual se le realizará la encuesta y proceso de selección a los participantes}

La encuesta será realizada a contadores públicos, los cuales han tenido experiencia como revisores fiscales en el último año enfocados en normatividad internacional en diferentes sectores y empresas de Colombia. La población objeto para la realización de la encuesta se eligió teniendo en cuenta sus estudios, trayectoria y experiencia en el campo de la auditoria y de las normas internacionales.

\section{Análisis de los resultados de la encuesta}

Los siguientes son los resultados de la encuesta desarrollada para los siete revisores fiscales y las respectivas preguntas planteadas:

1. ¿Desde hace cuánto tiempo ejerce las funciones de revisor fiscal?

Para la encuesta desarrollada se obtuvo la participación de revisores fiscales que tienen experiencia mayor a un año, esto permite llevar el enfoque de las respuestas a un mayor alcance, además de conocer a fondo cómo ha sido la aplicación de las normas antes de la adopción de las NIIF ahora cuando ya se están aplicando en empresas grupo 1.

Figura 2. Tiempo en ejercicio como revisor fiscal.
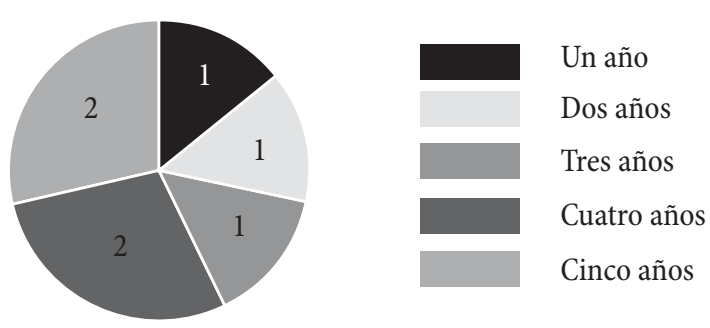

Fuente: elaboración propia. 
2. ¿En qué tipo de empresa y sectores ha tenido experiencia como revisor fiscal?

En esta pregunta es importante destacar que los participantes podían dar solución con opción múltiple, por lo cual se obtuvo mayor cantidad de respuestas en "Gran empresa" con un total de seis participantes, seguida de "Mediana empresa" con un total de dos participantes y tan solo un participante ha tenido experiencia en "Empresa pequeña", a partir de esto se identifica que las respuestas presentadas en las siguientes preguntas abarcan con mayor claridad el objetivo de la encuesta, el cual es el impacto de los NIIF en la revisoría fiscal.

Figura 3. Tipo de empresa en la que ha ejercido como revisor fiscal.

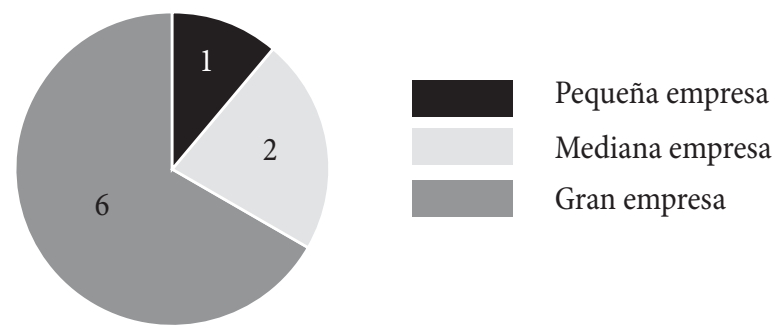

Fuente: elaboración propia.

Debido a la adopción de las NIIF en Colombia, el primer año de su implementación fue el 2015 para las grandes empresas o empresas pertenecientes a grupo 1 .

Por otro lado, la mayoría de los encuestados se desempeñan en el sector servicios con un total de siete participantes y en menor cantidad el sector industrial con un total de dos participantes, como se observa a continuación. 
Figura 4. Capacitación en NIIF y NIA.

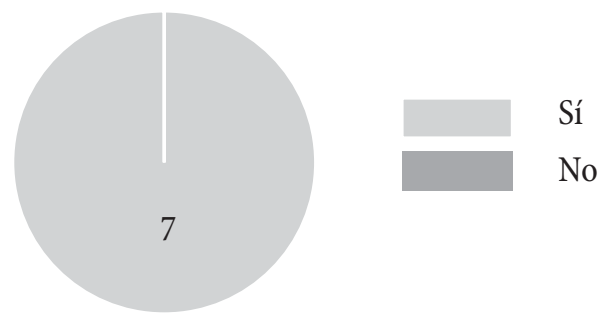

Fuente: elaboración propia.

Lo anterior permite abarcar las respuestas no solo en un sector específico, además de esto se identifica el análisis contable de varios sectores y permite abordar diferentes temas contables en cada una de las respuestas.

3. ¿Ha tenido alguna capacitación en Normas Internacionales de Información Financiera y de Auditoria?

La totalidad de la población encuestada ha recibido capacitaciones en Normas Internacionales de Información Financiera y de Auditoría, a la luz de lo cual se identifica que es un tema que abarca toda la ciencia contable, por lo cual existe la necesidad de actualizarse y permite que exista un avance positivo en términos de adopción de las normas internacionales.

Figura 5. Seguimiento a los profesionales contables por parte de la educación superior y los órganos de control.

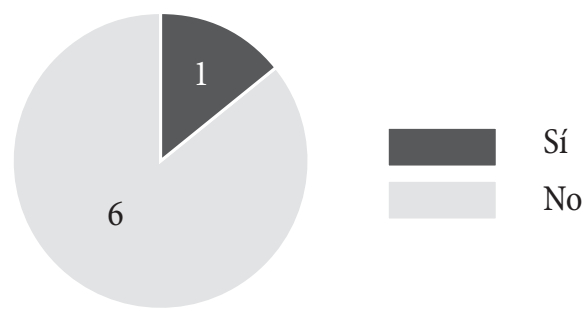

Fuente: elaboración propia. 
4. ¿Cree usted que las entidades de educación superior y los organismos de control han preparado a los profesionales contables y han realizado seguimiento oportuno en relación a la adopción de Normas Internacionales de Información Financiera en Colombia?

En la opinión de los participantes, seis de ellos dieron respuesta negativa, mientras que uno de los mismos dio respuesta positiva, es decir que para los participantes en su mayoría, las entidades de educación superior y los organismos de control no se han proyectado en la preparación de los profesionales contables, esto debido a varios temas específicos.

- Primero la adopción de las normas internacionales no es un proceso sencillo de asimilar, en sí son normas muy extensas.

- Los programas académicos de las universidades en Colombia están pasando al igual que toda la profesión por un proceso de cambio, esto permitió que profesionales contables tuviesen en su pensum institucional el cambio aun cuando ya se había iniciado el proceso.

- A partir de la Ley 1314 de 2009 hasta el año 2014, proceso en que iniciaba la adopción de las normas, transcurrió un tiempo adecuado para que las instituciones tomaran los correctivos necesarios, sin embargo ni las instituciones de control ni las educativas prepararon un plan de contingencia adecuado.

- El contador público se sigue dando a conocer como una figura de partida doble, pero no está dando un valor agregado en las empresas. En muchas ocasiones se pierde el criterio profesional, por sencillamente no encontrarse capacitado para dar una instrucción en las entidades.

- La falta de profesionales expertos en el tema que puedan brindar apoyo tanto a los organismos de control como a las entidades de educación.

A pesar de los temas anteriormente expuestos, cabe destacar que las universidades están ampliando su pensum en la profesión, así como las personas se están capacitando ya sea de forma independiente o mediante 
programas tales como diplomados o especializaciones, que permiten dar un paso a un tema extenso y de vital importancia en la profesión.

Por otro lado, las propias empresas están abriendo su capacidad de capacitación a sus empleados en estos temas, debido a que ya las empresas de grupo 1 están aplicando las normas, y a partir de este año las medianas empresas o de grupo 2 también conocidas hace explicita la obligación de capacitación.

5. ¿Cómo ha sido su experiencia como revisor fiscal teniendo en cuenta la adopción en Colombia de las Normas Internacionales de Información Financiera?

Para entender el cambio de la figura del revisor fiscal es importante indagar con los propios participantes cómo ha sido este proceso, destacando los principales impactos que ha tenido la norma, además de esto que los participantes en mayor cantidad han tenido experiencia en grandes empresas, las cuales ya pasaron por el proceso de adopción.

A continuación se presentan los principales impactos que permiten dar un paso respecto a cómo se puede actuar este año tanto para grandes como medianas empresas:

- Además de que el proceso de adopción no se adecuó en el tiempo indicado, se presenta desconocimiento de todos los profesionales contables respecto a la normativa a aplicar, a pesar del gran esfuerzo que han hecho unos pocos por estar inmersos en el tema.

- El tema fiscal es un punto fundamental, esto debido a que el Decreto 2649 de 1993 sigue siendo la base fiscal para la tributación en el país, lo que hace que se deba llevar contabilidad tanto por principios contables colombianos como por estándares internacionales.

- Tanto para el revisor fiscal como para las entidades a las cuales hace su revisoría, están en un proceso de aprendizaje continuo, lo que permite que la información deba ser reprocesada en varias ocasiones, 
información que va dirigida a las entidades de control y por lo tanto el reproceso en las mismas.

- El revisor fiscal terminó siendo en las grandes empresas un instructor de las normas internacionales, donde las entidades buscaban recibir asesoría en la materia. Esto último se puede analizar desde dos puntos: 1) las entidades dan por hecho que al ser revisor fiscal tiene los conocimientos adecuados para hacer su revisión, lo cual es cierto y por tanto implica que el profesional esté completamente preparado, esto da la obligación de esta figura de ser un asesor que requiere no solo estar capacitado sino además capacitar; 2) la evaluación por parte de las empresas debe ser constante, no esperar un asesoramiento del revisor fiscal únicamente, la capacitación independiente es fundamental en el desarrollo de la adopción.

Ante esto es de resaltar que el rol de revisor fiscal debe ser asumido como tal, teniendo en cuenta que es para las entidades colombianas de alguna forma un apoyo en las revisiones constantes, por tanto el conocimiento que debe adquirir hace que la profesión se torne un reto, densa e incluso exhaustiva.

6. ¿Cree usted que se le debe dar algún cambio a la función de revisoría fiscal en Colombia teniendo en cuenta la adopción de las Normas Internacionales de Información Financiera?

Las respuestas a las cuales llegamos mediante este cuestionamiento arrojaron como resultado que cuatro de los participantes están de acuerdo con que exista algún cambio en la figura del revisor fiscal, de acuerdo a este resultado, las siguientes son las conclusiones: 
Figura 6. Cambios en la función del revisor fiscal.

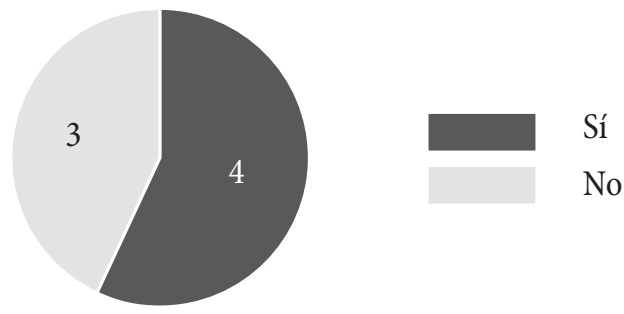

Fuente: elaboración propia.

- El adoptar las normas internacionales debe abrir la mente al contador a diversos temas no solo en la materia, tales como matemática financiera, valoración, avalúos, estadísticas, entre otros, esto con el fin de no dejar que los clientes pasen información y no se tenga la capacidad de hacer un análisis de las operaciones más allá de las cifras contables y la partida doble.

- Las entidades están buscando que el propio revisor fiscal sea un asesor, sin embargo como se identificó, esta no es una de las funciones de dicha figura, más allá de que puede dar un concepto de los procedimientos.

- Sale a la luz un tema de discusión y es hasta dónde llega el alcance del revisor fiscal, esto debido a revisiones que en muchas ocasiones son solicitadas por entidades gubernamentales, donde existe la obligación de firma de este, sin embargo con el solo hecho de la presentación de información por parte de cada entidad es suficiente, entre estas revisiones se encuentran: las certificaciones y la revisión de impuestos.

Por otro lado, tres de los participantes dieron respuesta a la pregunta con un "no" al cambio de las funciones, para estos las funciones deben continuar tal y como lo estipula el Código de Comercio, actuando de forma más rígida a nivel de políticas gubernamentales, así mismo se hace referencia a la 
importancia de esta figura recordando que aplica únicamente en Colombia y que ha permitido que de alguna forma las empresas no presenten información por presentar, si no que reciban las retroalimentaciones necesarias para un mejor desempeño.

7. De acuerdo a su criterio y experiencia profesional, mencione dos aspectos positivos y dos aspectos negativos de las Normas Internacionales de Información Financiera en Colombia.

Para dar respuesta a lo anterior es necesario aclarar los puntos positivos y negativos de acuerdo a las respuestas dadas por los participantes, a continuación se enuncia en primera instancia los principales aspectos positivos:

- De acuerdo al proceso de globalización que ha permitido la adopción de las normas internacionales en Colombia, permite que la información sea presentada de forma homogénea y entendible para todos los usuarios de la información.

- Los registros contables y la información se presentan de acuerdo a valor razonable y no a costo histórico como se venía realizando, esto permite que la información sea presentada con mayor confiabilidad teniendo en cuenta la información contable actual.

- El profesional de la contaduría pública ahora es una persona integral que realmente aportará su capacidad y conocimiento en NIIF, para diagnosticar financieramente una empresa y tomar decisiones acertadas.

- Existe la segregación de profesionales mediocres que ejercen como revisores fiscales y como contadores, permitiendo que quienes ejerzan la profesión sean personas capacitadas para tal labor y no aquellos que no ha tenido ni la capacitación ni la experiencia suficiente para el desarrollo de esta profesión. 
- Los profesionales tendrán mayor capacidad de análisis e investigación tanto en normas internacionales como en la aplicación de las mismas.

Los siguientes son los aspectos negativos más importantes para destacar:

- La adopción de las normas internacionales se dio a destiempo, por lo cual ni las empresas ni las entidades reguladoras, y por tanto las entidades de educación superior, no estaban preparadas para brindar el proceso de capacitación para los profesionales contables.

- De acuerdo a las normas adoptadas hace falta la claridad conceptual de las mismas, ya que son pocos los profesionales que se han capacitado, además de que a partir de los años 2016 y 2017 empieza la adopción de normas para entidades medianas y pequeñas que son la mayor cantidad de empresas en el país, y las mismas no se encuentran ni informadas ni capacitadas para la vinculación de las normas internacionales.

- La DIAN debió anticiparse al tema de la implementación de NIIF y haber emitido su posición frente a las normas con mucha más antelación a como está planteado; sus conceptos serán emitidos hasta el año 2018 y 2019, para los grupos 1 y 2 respectivamente, sobre el tratamiento de las NIIF a nivel tributario. Lo anterior ha generado confusión, entropía y caos en las empresas y en nuestros colegas, al llevar libros multipropósitos de contabilidad.

Cabe destacar que los participantes no han tenido la oportunidad de realizar la revisoría fiscal en entidades pequeñas, sin embargo debido a la complejidad que ha generado y al impacto que han sufrido las grandes empresas con la aplicación de las normas internacionales en el año 2015, se puede abarcar un tema ácido, ¿ cómo las entidades pertenecientes a grupos 2 y 3 en el país van a recibir la adopción de las normas internacionales? Y por otro lado, ¿cuál será el impacto contable en estas entidades? 
8. ¿Cree usted que con las normas internacionales se van a aumentar o disminuir los casos de corrupción of fraude financieros de las empresas colombianas?

Figura 7. Las NIIF frente a los casos de corrupción o fraude financiero.

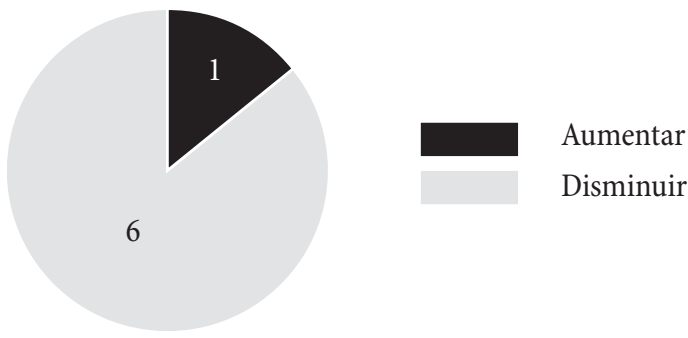

Fuente: elaboración propia.

Teniendo en cuenta las respuestas de los participantes, se evidenció que 6 de los mismos dieron como respuesta la disminución de los casos de corrupción, sin embargo en todos los casos se da una sola observación y es que la contabilidad creativa depende de la ética de cada uno de los profesionales, quien quiere hacer fraude utiliza su conocimiento y su oportunidad para infringir, sin embargo a mayor preparación tanto de las entidades de control como del propio revisor fiscal, es probable que dichos casos tiendan a disminuir, toda vez que la interpretación de las normas internacionales requieren de mayor alcance.

Estos controles que generará la entidad ante todo tipo de riesgos serán mucho más relevantes, debido a la presentación de información que se debe hacer a las entidades reguladoras. En el marco de los procesos de convergencia a normas internacionales de aseguramiento, las entidades reguladoras deben incrementar su capacidad para apoyar y vigilar a las entidades, así como para aumentar los espacios de capacitación, especialmente para las empresas denominadas Pymes pues representan el mayor número de unidades empresariales 
9. ¿De acuerdo a su experiencia como revisor fiscal las normas internacionales tuvieron un impacto en el desempeño financiero de las empresas a 31 de diciembre de 2015?

Figura 8. Impacto de las NIIF en el desempeño financiero al 31 de diciembre de 2015.

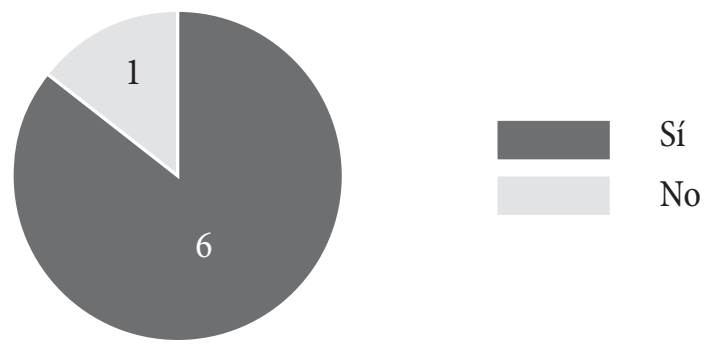

Fuente: elaboración propia.

Por último, se realizó la pregunta de si hubo o no impacto en la adopción de las NIIF para las grandes empresas quienes ya aplicaron esta normativa durante el año 2015, de lo anterior 6 de los participantes dan respuesta a que sí hubo impacto. A continuación se presentan los principales impactos a los cuales se vieron enfrentados los revisores fiscales durante las auditorías del año 2015:

- Mediciones tales como a valor razonable y no al costo, las cuales generan impactos en la empresa, así mismo el desempeño financiero debido a reconocimientos que bajo norma internacional no aplica y que permite la distorsión de los estados financieros.

- Los órganos de control no se encuentran lo suficientemente capacitados para comprender la información financiera internacional, lo que permite que aunque la información sea presentada, no se incluya un proceso álgido para su revisión.

- Los procedimientos para aplicar las normas internacionales son mucho más robustos, por lo cual hay temas que aún no están revisados al 
$100 \%$, que se dejaron pasar por alto o que por falta de conocimiento no se tuvieron en cuenta en la evaluación del desempeño financiero para el año 2015.

Por otro lado, en aquellas organizaciones en las que la implementación no tuvo impacto podría deducirse que dichos impactos dependen también de los procesos que lleva a cabo cada entidad, así como el sector que ocupa dentro de la economía, lo que permite afectaciones en cuentas de los estados financieros, que a su vez genera impactos en revelaciones. Sin embargo, los ajustes realizados, así como los cambios en estimaciones, no han tenido gran impacto.

\section{Conclusiones}

A lo largo de la historia de la profesión contable se ha dado la importancia de una figura que permita dar confianza a los usuarios de la información, a las entidades reguladoras y a la propia empresa. Con el nacimiento de la figura del revisor fiscal en Colombia ha permitido que dicha confianza se materialice, a través de la regulación específica donde se encuentra qué entidades están obligadas a tener un revisor fiscal, pasando por las funciones que debe cumplir estipuladas en el Código de Comercio de Colombia, así como el procedimiento de elección en las entidades y el enfoque de su profesión.

Es de vital importancia destacar los principios por los cuales se debe regir el revisor fiscal para lograr recuperar la credibilidad de los inversionistas principalmente, debido a los diferentes casos de corrupción tanto internacional como nacional. Y es que al momento de existir cualquier tipo de caso de corrupción uno de los primeros interrogantes que se hacen los afectados es, ¿dónde está el revisor fiscal o el profesional contable encargado de revisar las actividades de las entidades?

Cabe aclarar que la función del revisor fiscal no está meramente en encontrar fraudes en las entidades, pero sí a partir de sus pruebas de auditoría y mediante el dictamen entregado a la empresa y a las entidades regulatorias, 
está dando la certeza de que sus procedimientos han sido evaluados con suficiencia y los mismos están soportados con evidencia física y respaldados mediante sus papeles de trabajo obligatorios.

Ahora bien, la profesión contable en Colombia está pasando por la adopción de las Normas Internacionales de Información Financiera - NIIF, y el revisor fiscal no puede ni debe estar alejado de este tema tan importante en la profesión, por tal razón se dedicó un apartado a lo largo del documento con el fin de, primero identificar las diferencias entre revisor fiscal y auditor, identificando el enfoque de trabajo de los mismos y cómo mediante el desarrollo de estas dos líneas contables permite mayor regulación y control en las empresas, en segunda instancia se destaca la investigación realizada referente a cuál es la visión de la figura del revisor fiscal tanto en norma nacional como en norma internacional.

A esto último es de vital importancia destacar que mediante la norma internacional se permite dar un enfoque más dirigido a la información financiera, ya que hoy por hoy el revisor fiscal está obligado a certificación todo tipo de información, por lo cual se logra recuperar las funciones que en principio fueron dispuestas para ejercer esta profesión.

Uno de los aspectos fundamentales para concluir y dar respuesta al tema que nos hemos propuesto es el análisis de la encuesta realizada, a partir de la cual se da respuesta a los objetivos planteados. Al hablar de cómo se va a ver afectada la figura del revisor fiscal teniendo en cuenta las Normas Internacionales de Información Financiera y cuál es el efecto de esta normatividad en el desarrollo de sus funciones, se concluye que es un reto para los profesionales, primero porque no todos los revisores fiscales cuentan con un amplio conocimiento y capacitación en temas de normas internacionales, lo cual dificulta el buen desarrollo de sus funciones y de igual forma por ser tan reciente este cambio de normatividad, segundo porque las empresas tampoco cuentan con conocimientos amplios y claros en el proceso de adopción de las normas internacionales, de forma que buscan un concepto acertado de la figura del revisor fiscal, que les sirva 
como soporte para mejorar su desempeño y adecuar los nuevos procedimientos que se avecinan.

Como lo enfatiza un revisor fiscal que a corte del 31 de diciembre de 2015 las empresas del grupo 1 en sus estados financieros presentaron pérdidas en el ejercicio contable, la justificación es principalmente por el cambio de normatividad.

Por tal razón las grandes empresas deben tomar medidas para que los resultados con corte a 31 de diciembre del 2016 sean satisfactorios, de igual forma las medianas empresas que inician su aplicación para el año 2016, y no dejar a un lado las Pymes, quienes ocupan el mayor porcentaje las empresas en el país y para las cuales no se ve un proceso de capacitación de las mismas por parte de los órganos de control.

Es por esta razón que el contador público, en especial el revisor fiscal, tienen un reto que debe generar un impacto en la profesión, de igual manera es importante que los órganos de control de la profesión analizaran y evaluaran las funciones y el alcance del revisor fiscal actual en cuanto a revisiones de temas tributarios, certificados y lo enfocaran hacia un proyecto más objetivo en cuanto a temas de normatividad internacional se refiere.

\section{Referencias}

Acero, A., y Cárdenas, C. (28 de noviembre de 2011). La revisoría fiscal frente a las Normas Internacionales de Información Financiera. Universidad Militar Nueva Granada. Recuperado de http://repository.unimilitar.edu.co/bitstream/10654/7140/2/AceroGarzonAndresJota2011.pdf

Bernal, A. V., Penagos, J. J., y Penagos, Y. I. (2014). Incidencia que tiene la implementación de normas internacionales con la revisoría fiscal en Colombia. Universidad de Cundinamarca. Recuperado de https://aprendeenlinea.udea. edu.co/revistas/index.php/adversia/article/download/11711/10670

Congreso de Colombia. (3 de febrero de 1961). Reglamenta el ejercicio de la profesión de contador público. [Ley 145 de 1960]. DO: 30.433. 
Congreso de Colombia. (13 de diciembre de 1990). Adiciona a la Ley 145 de 1960 y reglamenta la profesión de contador público y se dictan otras disposiciones. [Ley 43 de 1990]. DO: 39.602.

Congreso de Colombia. (18 de diciembre de 1990). Se expiden normas en materia de intermediación financiera, se regula la actividad aseguradora, se conceden unas facultades y se dictan otras disposiciones. [Ley 45 de 1990]. Recuperado de https://www.superfinanciera.gov.co/descargas?com=institucional\&name $=$ pubFile13523\&downloadname=art6ley45fidu.pdf

Congreso de Colombia. (6 de junio de 1995). Se dictan normas tendientes a preservar la moralidad en la Administración Pública y se fijan disposiciones con el fin de erradicar la corrupción administrativa. [Ley 190 de 1995]. DO: 41.878. Congreso de Colombia. (20 de diciembre de 1995). Modifica el Libro II del Código de Comercio y se expide un nuevo régimen de procesos concursales y se dictan otras disposiciones. [Ley 222 de 1995]. DO: 42.156.

Congreso de Colombia. (13 de julio de 2009). Regula los principios y normas de contabilidad e información financiera en Colombia. [Ley 1314 de 2009]. DO: 47.409. Contaduría General de la Nación. (s.f.). Utilidad y usuarios de la información contable pública. Contaduría General de la Nación. Recuperado de http://www.contaduria.gov.co/wps/wcm/connect/cla0c65b-0caa-416b-a2af-c39da34d5838/cap5. pdf?MOD=AJPERES\&CACHEID=c1a0c65b-0caa-416b-a2af-c39da34d5838

Diamond, A. (2005). Normas Internacionales de Informacion Financiera y su aplicación en Panamá. Panamá: KPMG. Recuperado de https://www.sefin.gob. $\mathrm{hn} / \mathrm{wp}$-content/uploads/2013/05/niif.pdf

Duque, O., y Moreno, G. (2015). Valoración de las prácticas de integración académica universitaria, para reducir el abandono de estudiantes de Contaduría Pública. En prensa.

Gómez, Y. (2012). Revisoría fiscal: mito o realidad colombiana. Universidad de Antioquia. Recuperado de https://aprendeenlinea.udea.edu.co/revistas/index. php/adversia/article/viewFile/11305/10338

Hernández, R., Fernández, C., y Baptista, P. (2010). Metodología de la Investigación (5 ed.). México, D. F.: McGraw-Hill.

López, G. J. (2013). Estados financieros auditados por el revisor fiscal, según las NIA clarificadas. Bogotá: Superintendencia de Sociedades. Recuperado de https://goo.gl/tO2CLc 
138 ACTivos | Mónica Alexandra Ahumada Quiroga, Edwin Steven Matallana Chilito, David Leonardo Ardila Segura

Moya, L. H. (2007). La revisoría fiscal frente a las normas internacionales de auditoría. Bogotá: Universidad Javeriana. Recuperado de https://www.javeriana.edu.co/personales/hbermude/nov/memorias_rev_fiscal_foro_firmas/ eventos_rev_fiscal/1er_encuentro_rev_fiscal/UCooperativaHenryMoya.pdf

Peña, J. M. (2011). Revisoría fiscal. Una garantía para la empresa, la sociedad y el Estado. Bogotá: Ecoe Ediciones.

Ruiz, R. F. (julio de 2015). Crisis de la revisoria fiscal. Quiroga, F. E. (Ed.). Líder absoluto la nota contable, (6), 5-13.

Secretaría General de la Alcaldía Mayor de Bogotá. (20 de febrero de 2015). Reglamenta la Ley 1314 de 2009 sobre el marco técnico normativo para las normas de aseguramiento de la información. [Decreto 302 de 2015]. DO: 49.431.

Secretaría General de la Alcaldía Mayor de Bogotá. (27 de marzo de 1971). Código del Comercio. [Decreto 410 de 1971]. DO: 33.339.

Secretaría General de la Alcaldía Mayor de Bogotá. (29 de diciembre de 1993). Reglamenta la contabilidad en general y se expiden los principios o normas de contabilidad generalmente aceptados en Colombia. [Decreto 2649 de 1993]. DO: 41.156 .

Superintendencia de Sociedades. (2013). Circular externa 115-000011 de 2013. Bogotá: Superintendencia de Sociedades. Recuperado de http://www.supersociedades.gov.co/superintendencia/normatividad/circulares-externas/ Normatividad\%20Circulares\%20Externas/32892.pdf

Superintendencia Financiera de Colombia. (26 de diciembre de 2013). Circular externa 038 de 2013. Bogotá: Superintendencia Financiera. Recuperado de www.superfinanciera.gov.co/descargas\%3Fcom\%3Dinstit ucional\%26name\%3DpubFile1005373\%26downloadname\%3Dce038_13. $\mathrm{doc}+\& \mathrm{~cd}=1 \& \mathrm{hl}=\mathrm{es}-419 \& \mathrm{ct}=\mathrm{clnk} \& \mathrm{gl}=\mathrm{co}$ 


\section{Anexo 1}

\section{ENCUESTA}

Agradecemos su ayuda con el diligenciamiento de esta encuesta. La información que nos proporcione será utilizada en la investigación titulada: Impacto y análisis de las normas internacionales en el desarrollo de las funciones del revisor fiscal en Colombia.

Se solicita responda a conciencia, sus respuestas serán tratadas de forma confidencial.

IDENTIFICACIÓN:

NOMBRE:

CARGO:

A continuación, usted encontrará varios tipos de preguntas, la primera opción múltiple con única respuesta, segundo opción múltiple con múltiples respuestas y por último preguntas abiertas.

\section{Opción múltiple con única respuesta}

1. ¿Desde hace cuánto tiempo ejerce las funciones de revisor fiscal?

\begin{tabular}{|c|c|c|c|c|c|c|}
\hline $\begin{array}{c}\text { Menor a } \\
\text { un año }\end{array}$ & Un año & Dos años & Tres años & Cuatro años & Cinco años & $\begin{array}{c}\text { Mayor a } \\
\text { cinco años }\end{array}$ \\
\hline & & & & & & \\
\hline
\end{tabular}

\section{Opción múltiple con múltiples respuestas}

2. ¿En qué tipo de empresa y sectores ha tenido experiencia como revisor fiscal? 
140 ACTivos | Mónica Alexandra Ahumada Quiroga, Edwin Steven Matallana Chilito, David Leonardo Ardila Segura

\begin{tabular}{|l|l|}
\hline \multicolumn{2}{|c|}{ TIPO DE EMPRESA } \\
\hline Pequeña empresa & \\
\hline Mediana empresa & \\
\hline Gran empresa & \\
\hline
\end{tabular}

\begin{tabular}{|l|l|}
\hline \multicolumn{2}{|c|}{ SECTOR } \\
\hline Sector agropecuario & \\
\hline Sector industrial (industrial extractivo, industrial de transformación) & \\
\hline $\begin{array}{l}\text { Sector terciario o de servicios (sector financiero, sector de comunicaciones, } \\
\text { sector minero y energético, sector de transporte, sector de comercio) }\end{array}$ & \\
\hline
\end{tabular}

\section{Preguntas abiertas}

3. ¿Ha tenido alguna capacitación en Normas Internacionales de Información Financiera y de Auditoria?

$$
\text { Sí__ No }
$$

4. ¿Cree usted que las entidades de educación superior y los organismos de control han preparado a los profesionales contables y han realizado seguimiento oportuno en relación a la adopción de Normas Internacionales de Información Financiera en Colombia?

Sí___ No

Por qué

5. ¿Cómo ha sido su experiencia como revisor fiscal teniendo en cuenta la adopción en Colombia de las Normas Internacionales de Información Financiera? 
6. ¿Cree usted que se le debe dar algún cambio a la función de revisoría fiscal en Colombia teniendo en cuenta la adopción de las Normas Internacionales de Información Financiera?

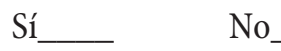

Por qué

7. De acuerdo a su criterio y experiencia profesional, mencione dos aspectos positivos y dos aspectos negativos de las Normas Internacionales de Información Financiera en Colombia.

8. ¿Cree usted que con las normas internacionales se van a aumentar o disminuir los casos de corrupción o fraude financieros de las empresas Colombianas?

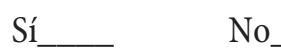

Por qué 
9. ¿De acuerdo a su experiencia como revisor fiscal, las Normas Internacionales de Contabilidad e Información tuvieron un impacto en el desempeño financiero de las empresas a 31 de diciembre de 2015?

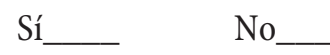

Por qué

\section{Agradecemos el tiempo invertido en esta actividad.}

Esta encuesta tiene como objetivo: identificar el efecto de las Normas Internacionales de Información Financiera y las Normas Internacionales de Auditoria en cuanto al papel del revisor fiscal en Colombia y de qué forma se va a ver afectada esta figura desde las normas adoptadas.

Este documento fue elaborado por Mónica Alexandra Ahumada Quiroga, Edwin Steven Matallana Chilito y David Leonardo Ardila Segura, estudiantes investigadores del Semillero de Investigación en Educación y Teoría contable (SINETCO), bajo la asesoría de Ruth Alejandra Patiño, docente directora del CICOP.

Fuente: elaboración propia. 